\title{
CORRECTION
}

\section{Correction to: Measurements of Sn Ejecta Particle-Size Distributions Using Ultraviolet In-line Fraunhofer Holography}

\author{
D. S. Sorenson ${ }^{1}$ (1) - G. A. Capelle ${ }^{3} \cdot$ M. Grover ${ }^{3} \cdot$ R. P. Johnson ${ }^{1}$ - M. I. Kaufman ${ }^{2}$ - B. M. LaLone ${ }^{3} \cdot$ R. M. Malone ${ }^{2}$.

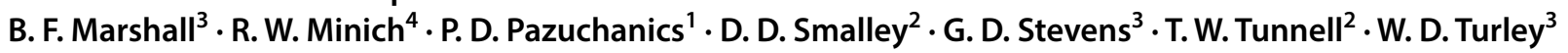

Published online: 18 May 2018

(c) Society for Experimental Mechanics, Inc 2018

\section{Correction to: \\ Journal of Dynamic Behavior of Materials (2017) 3:233-239 \\ https://doi.org/10.1007/s40870-017-0105-7}

The right side of Fig. 5 has the square symbols mislabeled. The square symbols should be labeled as median instead of mean. The text that references the figure should also be understood as referring to the median and not the mean. The authors wish to thank Martin Schauer from P-21, Los Alamos National Laboratory for suggesting this possible error.

The original article can be found online at https://doi.org/10.1007/ s40870-017-0105-7.

\section{S. Sorenson}

sorenson@lanl.gov

Los Alamos National Laboratory, Los Alamos, NM, USA

2 NSTec, LLC, Los Alamos, NM, USA

3 NSTec, LLC, Special Technologies Laboratory, Santa Barbara, CA, USA

4 Lawrence Livermore National Laboratory, Livermore, CA, USA 